\title{
Correction to: A Versatile Vector Toolkit for Functional Analysis of Rice Genes
}

Feng $\mathrm{He}^{1,2}$, Fan Zhang ${ }^{1}$, Wenxian Sun ${ }^{2}$, Yuese Ning ${ }^{1 *}$ and Guo-Liang Wang ${ }^{1,3^{*}}$

\section{Correction}

The caption of Fig. 5 contained an error. The updated caption along with the original figure is published in this correction article.

Table S1 in the Additional file of this original publication contained some errors. The updated Table S1 is published in this correction article.

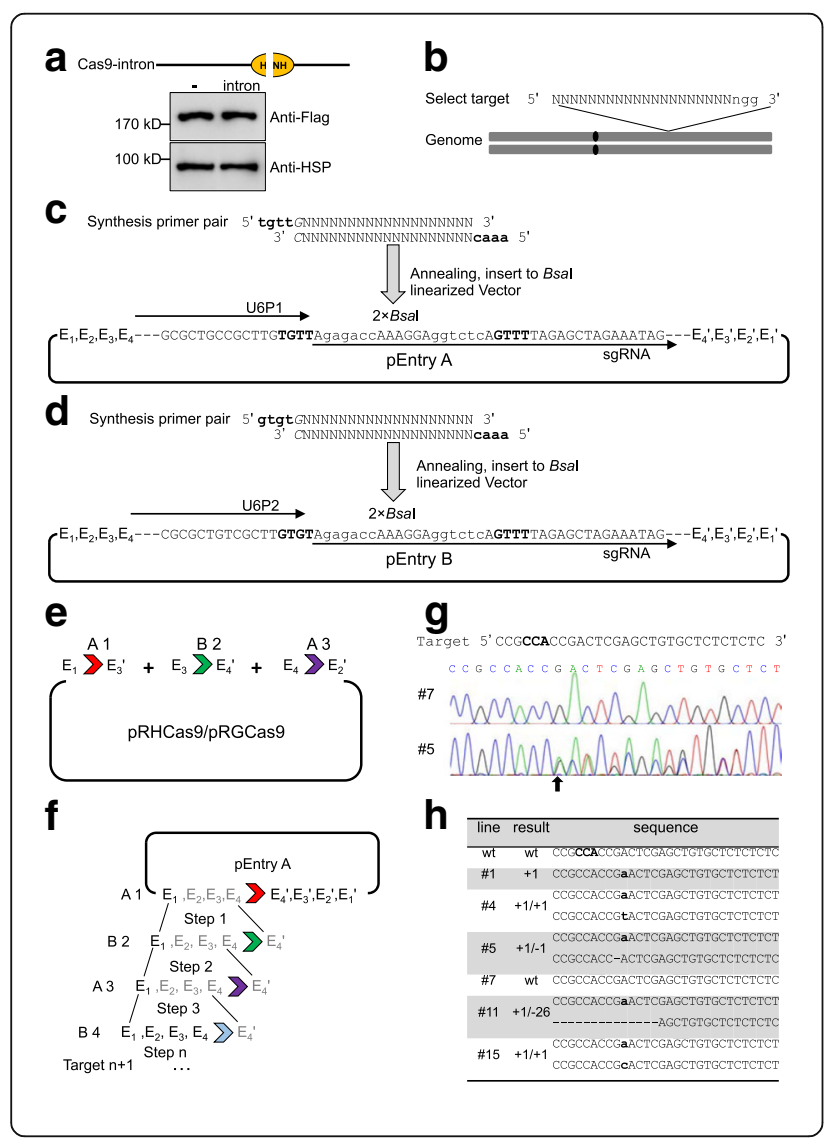

Fig. 5 Diagram of how CRISPR/Cas9 vectors were constructed and used to edit the rice IPAI gene. a Western blot analysis of the Cas9intron expression in rice protoplasts. HSP indicates the loading amount of each sample. $\mathbf{b}$ Target site selection for candidate genes in the rice genome. A 20-bp specific sequence followed by the PAM "NGG" structure is required. $\mathbf{c}$ and $\mathbf{d}$ Target cloning to the entry vectors. Synthesis of the primer pairs of the 20-bp specific target with the 4-bp adapters, and ligation with the Bsal linearized pEntry A or pEntry B vector. e One-step ligation and $\mathbf{f}$ step-by-step ligation of multiple targets to pRHCas9/pRGCas9. Four pairs of isocaudamers, Pstl(E1)-Nsil(E1'), Xbal(E2)-Spel(E2'), BamHI(E3)-Bglll(E3'), and Sall(E4)Xhol(E4') are marked. The sgRNA cassettes with U6P1 and U6P2 in pEntry A and B should be used in turn. $\mathbf{g}$ Representative sequencing chromatogram of the CRISPR-IPA 1 transgenic lines. Line \#7, wild-type genotype; line \#5, mutant genotype. $\mathbf{h}$ Representative gene editing results in the CRISPR-IPA1 transgenic lines

\section{Additional file}

Additional file 1: Updated Table S1, the full supplementary materials can be downloaded from the original publication. (XLSX $10 \mathrm{~kb}$ )

\section{Author details}

${ }^{1}$ State Key Laboratory for Biology of Plant Diseases and Insect Pests, Institute of Plant Protection, Chinese Academy of Agricultural Sciences, Beijing 100193, China. ${ }^{2}$ College of Plant Protection, China Agricultural University, Beijing 100193, China. ${ }^{3}$ Department of Plant Pathology, The Ohio State University, Columbus, OH 43210, USA.

Published online: 07 September 2018

\section{Reference}

He F et al (2018) A Versatile Vector Toolkit for Functional Analysis of Rice Genes. Rice 11:27. https://doi.org/10.1186/s12284-018-0220-7

\footnotetext{
* Correspondence: ningyuese@caas.cn; wang.620@osu.edu

'State Key Laboratory for Biology of Plant Diseases and Insect Pests, Institute of Plant Protection, Chinese Academy of Agricultural Sciences, Beijing
} 100193, China

\section{Springer Open}

(c) The Author(s). 2018 Open Access This article is distributed under the terms of the Creative Commons Attribution 4.0 International License (http://creativecommons.org/licenses/by/4.0/), which permits unrestricted use, distribution, and reproduction in any medium, provided you give appropriate credit to the original author(s) and the source, provide a link to the Creative Commons license, and indicate if changes were made. 